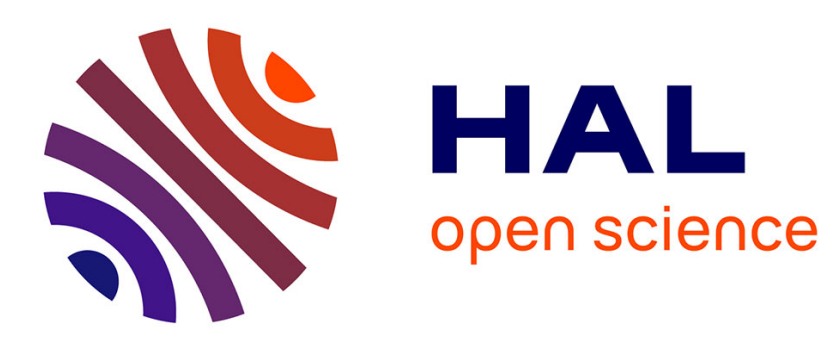

\title{
DEMETER observations of the ionospheric trough over HAARP in relation to HF heating experiments
}

\author{
D. Piddyachiy, T. F. Bell, Jean-Jacques Berthelier, U. S. Inan, Michel Parrot
}

\section{To cite this version:}

D. Piddyachiy, T. F. Bell, Jean-Jacques Berthelier, U. S. Inan, Michel Parrot. DEMETER observations of the ionospheric trough over HAARP in relation to HF heating experiments. Journal of Geophysical Research Space Physics, 2011, 116, pp.A06304. 10.1029/2010JA016128 . hal-00578970

\section{HAL Id: hal-00578970 \\ https://hal.science/hal-00578970}

Submitted on 10 Jan 2016

HAL is a multi-disciplinary open access archive for the deposit and dissemination of scientific research documents, whether they are published or not. The documents may come from teaching and research institutions in France or abroad, or from public or private research centers.
L'archive ouverte pluridisciplinaire HAL, est destinée au dépôt et à la diffusion de documents scientifiques de niveau recherche, publiés ou non, émanant des établissements d'enseignement et de recherche français ou étrangers, des laboratoires publics ou privés. 


\title{
DEMETER observations of the ionospheric trough over HAARP in relation to HF heating experiments
}

\author{
D. Piddyachiy, ${ }^{1}$ T. F. Bell, ${ }^{1}$ J.-J. Berthelier, ${ }^{2}$ U. S. Inan, ${ }^{1,3}$ and M. Parrot ${ }^{4}$ \\ Received 17 September 2010; revised 10 March 2011; accepted 17 March 2011; published 3 June 2011.
}

[1] Plasma density variations observed aboard the DEMETER satellite in the topside ionospheric $F$ layer are analyzed in relation to high-frequency transmitter operations. The main interest is the high-latitude region. One hundred cases with operating and nonoperating High Frequency Active Auroral Research Program HF transmitter during day and night are examined. It is found that most large-scale variations can be attributed to the presence of the main ionospheric trough and that such natural variations complicate the detection of HF transmitter effects on a case-by-case basis. From statistics, no correlation between the HF transmissions and the presence of the irregularities has been established. A comparison of our observations with two recent works on electron density ducts created by HF transmitters and detected by DEMETER shows that in those works the main ionospheric trough is the major factor in density variations, and it is not clear how to distinguish density variations created by the HF heater from natural variations in such cases. Finally, possible experimental techniques for duct formation by HF heaters are discussed.

Citation: Piddyachiy, D., T. F. Bell, J.-J. Berthelier, U. S. Inan, and M. Parrot (2011), DEMETER observations of the ionospheric trough over HAARP in relation to HF heating experiments, J. Geophys. Res., 116, A06304, doi:10.1029/2010JA016128.

\section{Introduction}

[2] Recently there have been several attempts to demonstrate the modification of the ionospheric plasma density by powerful high frequency (HF) heaters situated in high-latitude regions [Milikh et al., 2008; Wong et al., 2009]. In these works the variation of plasma density is attributed to HF heating. However, the detection of HF-generated density modifications is generally a complicated problem in this region, because it is directly affected by the solar wind and energetic particles from the Earth's magnetosphere, and as a consequence the ionospheric parameters there are more variable than at lower latitudes [Hunsucker and Hargreaves, 2003]. One important feature of the ionosphere above the HAARP HF heater which introduces variability is the main ionospheric trough. Unfortunately, this feature was not discussed in works of Milikh et al. [2008] and Wong et al. [2009], although satellite observations from those works show the presence of the main trough.

[3] The main ionospheric trough, often also called the midlatitude trough [Kelley, 2009], is a region at $F$ layer alti-

\footnotetext{
${ }^{1}$ Department of Electrical Engineering, Stanford University, Stanford, California, USA.

${ }^{2}$ Centre d'Etudes des Environnements Terrestre et Planétaires, IPSL, Saint-Maur-des-Fossés, France.

${ }^{3}$ Electrical Engineering Department, Koç University, Sariyer-Istanbul, Turkey.

${ }^{4}$ Laboratoire de Physique et Chimie de l'Environnement, CNRS, Orléans, France.

Copyright 2011 by the American Geophysical Union. 0148-0227/11/2010JA016128
}

tudes and in the topside ionosphere, where the plasma, dominated by heavy $\mathrm{O}^{+}$ions, is depleted and usually displays irregularities of large amplitude. The main trough is limited in latitudinal width but extended in the east-west direction and marks the boundary between high- and middle-latitude regions of the ionosphere [Hunsucker and Hargreaves, 2003]. In general, the trough can be observed at invariant latitudes of $50^{\circ}-70^{\circ}$, and it has a latitudinal width up to $10^{\circ}$, but these figures are highly variable. The main trough is mostly a nightside phenomenon and moves to lower latitudes with increasing geomagnetic activity. The basic cause of the main ionospheric trough is considered to be the structure of ion convection paths in which some of the paths do not encounter a production region for several hours, which is enough for the plasma density to decay [Rodger et al., 1992]. The ionospheric trough is the place where subauroral jets (regions with increased convection velocity and high $T_{i}$ due to ion/neutral collisional heating) occur.

[4] Another important phenomenon observed in the region above HAARP is ELF electrostatic turbulence. ELF electrostatic turbulence often disrupts satellite observations of ELF waves generated by ionospheric modification with the HAARP HF transmitter. In the work of Piddyachiy et al. [2008] several ELF pulses are masked by the presence of ELF electrostatic turbulence. ELF electrostatic turbulence prevents the detection of those pulses at DEMETER altitude but not their generation due to HF heating, because the generation occurs at lower altitudes in the $D$ region [Moore et al., 2007]. Overall, ELF electrostatic turbulence should be taken into account during the analysis of ELF waves produced by such active experiments. 
[5] The name "electrostatic turbulence" was given to the phenomenon observed in this work in the pioneering paper by Kelley [1972]. Here we call it "ELF electrostatic turbulence" to distinguish from other types of electrostatic turbulence found in literature [e.g., Berthelier et al., 2008]. The main signature of ELF electrostatic turbulence is the presence of broadband impulsive perturbations from $\mathrm{DC}$ up to a few $\mathrm{kHz}$ in the electric field and no corresponding perturbations in the magnetic field in the frequency range DEMETER can reliably observe ( $\sim 100 \mathrm{~Hz}$ to $20 \mathrm{kHz})$. Because of the previously established association of ELF electrostatic turbulence with density irregularities [Kelley, 1972; Temerin, 1978; Kelley, 2009; and references therein], ELF $E$ field recordings of electrostatic turbulence can in fact be used as an additional diagnostic tool to determine the location and structure of such irregularities.

[6] In this work we present DEMETER satellite observations of the ionospheric trough and density irregularities in relation to HF transmitter operation. First, we show specific cases which demonstrate that the trough and density irregularities can occur in the region over HAARP as well as in regions well displaced from the HAARP location. Then, making use of data from 100 passes of DEMETER over HAARP we show that there is no apparent correlation between the trough observations and HF transmitter transmissions. The observations demonstrate that the ionospheric trough is often observed in the region near HAARP and generally constitutes the dominant component of all density variations in this region. Afterward, a comparison with works of Milikh et al. [2008] and Wong et al. [2009] shows that the effects presented therein can be attributed not only to HF heating but to natural density variations in the main trough also. The implication of the trough presence in relation to HF heating experiments is discussed at the end.

\section{Experimental Setup}

[7] The main part of our experiment consists of measurements on the DEMETER satellite over the region of the HAARP HF transmitter in the high-latitude ionosphere $\left(50^{\circ}-70^{\circ}\right)$.

[8] The high-frequency ionospheric heater used herein [Kennedy and Kossey, 2002] is a component of the High Frequency Active Auroral Research Program (HAARP) facility located near Gakona, Alaska, at the geographic position of $62.39^{\circ} \mathrm{N}, 145.15^{\circ} \mathrm{W}$, corresponding to the magnetic shell $\mathrm{L} \simeq$ 4.9. The HAARP HF heater consists of a 180-element phased array antenna fed by distributed transmitters at each antenna element with total maximum continuous power of 3.6 MW. HAARP can operate at $\mathrm{HF}$ frequencies ranging from $2.7 \mathrm{MHz}$ to $10 \mathrm{MHz}$, and in the experiments described below it was used at $2.75-3.25 \mathrm{MHz}$ to provide maximum heating in the $D$ region of the ionosphere [James et al., 1984]. At $3.25 \mathrm{MHz}$ the net radiated power is $3.2 \mathrm{MW}$, the antenna array gain is $21 \mathrm{~dB}$, the effective radiated power (ERP) at the center of the beam is $407 \mathrm{MW}$, and the full width half-power beam width is $17.2^{\circ}$ in the north-south plane and $13.5^{\circ}$ in the east-west plane. In most of our experiments the HF beam was directed vertically upward and the HF carrier was modulated with different types of ELF/VLF modulation which effectively reduces the average HF power by a factor of two.

[9] DEMETER is a low Earth orbit satellite with an altitude of approximately $670 \mathrm{~km}$, inclination of $98.3^{\circ}$ and horizontal velocity of about $7.6 \mathrm{~km} / \mathrm{s}$ [Parrot, 2006]. It is a three-axis stabilized spacecraft, i.e., nonspinning. For HAARP experiments, DEMETER operated in the burst mode. In this mode the satellite can record 3 components of DC/ULF $\mathbf{E}$ field up to $19.5 \mathrm{~Hz} ; 3$ components of both ELF $\mathbf{E}$ and B fields up to $1.25 \mathrm{kHz}$; one component of each field up to $20 \mathrm{kHz}$ (VLF) and HF E field power spectra up to $3.33 \mathrm{MHz}$. ICE is an abbreviation used for the electric field instrument and IMSC for the magnetic field instrument. Electron and ion densities can be measured by two types of instruments: a Langmuir probe (ISL) and a thermal plasma analyzer (IAP). For HAARP experiments, DEMETER burst recordings were specially extended beyond the normal termination at the invariant latitude of $65^{\circ}$.

[10] For this work, ICE and IMSC were used in the VLF mode. ICE sensors are deployed on booms 4 meters from the satellite [Berthelier et al., 2006]. The component of $E$ field reported here is a horizontal component perpendicular to the orbital plane. ICE has a sensitivity of $\sim 0.1 \mu \mathrm{V} / \mathrm{m} \mathrm{Hz}^{1 / 2}$, and the dynamic range is $>80 \mathrm{~dB}$. The search coil magnetometers of IMSC are mounted at the end of a $1.9 \mathrm{~m}$ boom and have a sensitivity of $-28 \mathrm{dBpT}$ at $1 \mathrm{kHz}$ [Parrot, 2006]. In this work the horizontal component of $\mathbf{B}$ inclined at $45^{\circ}$ to the $E$ field component is used.

[11] The DEMETER Langmuir probe measures primarily the electron density $N_{e}$ and electron temperature $T_{e}$ with $1 \mathrm{~s}$ time resolution [Lebreton et al., 2006]. $N_{e}$ can be measured in the range of $10^{8}-5 \cdot 10^{11} \mathrm{~m}^{-3}$ and $T_{e}$ in the range of $600-10,000 \mathrm{~K}$. Accuracies of $\pm 30 \%$ for $N_{e}$ and $\pm 15 \%$ for $T_{e}$ are generally accepted for the situations in which the real ionospheric plasma with bulk motion and magnetic field effects is approximated by "ideal" plasma conditions, i.e., Maxwellian distributions. Due to contamination of the ISL probe at launch, the measured values of $T_{e}$ are in general significantly higher than real ones by about $800 \mathrm{~K}$ for a mean temperature of $\sim 2500$ to $3000 \mathrm{~K}$. Lebreton et al. [2006] also noted that under auroral plasma conditions the plasma parameters may be inaccurate in absolute value but their variations may still be identified. Data for ion densities and temperature from IAP are used as auxiliary data in this work. It should be noted that sometimes unusually high peaks in ion temperature are seen, e.g., on 26 February 2007 07:13 UT. Most often they are overestimated due to the specifics of automatic data processing, but this topic is out of the scope of the current work since it does not affect its results.

[12] A typical representation of data from instruments used in this work is shown in Figure 1. Figure 1a contains an onboard spectrogram from ICE for HF frequencies relevant to each experiment. Figure $1 b$ is an onboard spectrogram from ICE in the ELF range that contains the effect discussed in this work. Figures $1 \mathrm{c}$ and $1 \mathrm{~d}$ show corresponding recordings of $N_{e}$ and $T_{e}$ measured by the DEMETER Langmuir probe. Figures 1e and 1f represent ion density (usually just the dominant ions $\mathrm{O}^{+}$) and ion temperature measured by IAP. In this work we are interested in the variation of these parameters. Also the trajectory of DEMETER projected vertically onto the ground is shown on a map. Crosses on the satellite path correspond to five time and position labels below the panels. A red dashed vertical line marks the closest approach of the DEMETER subsatellite point to HAARP, and vertical black dotted lines mark the approximate boundaries of the main trough. When referring to a distance between the satellite and a 


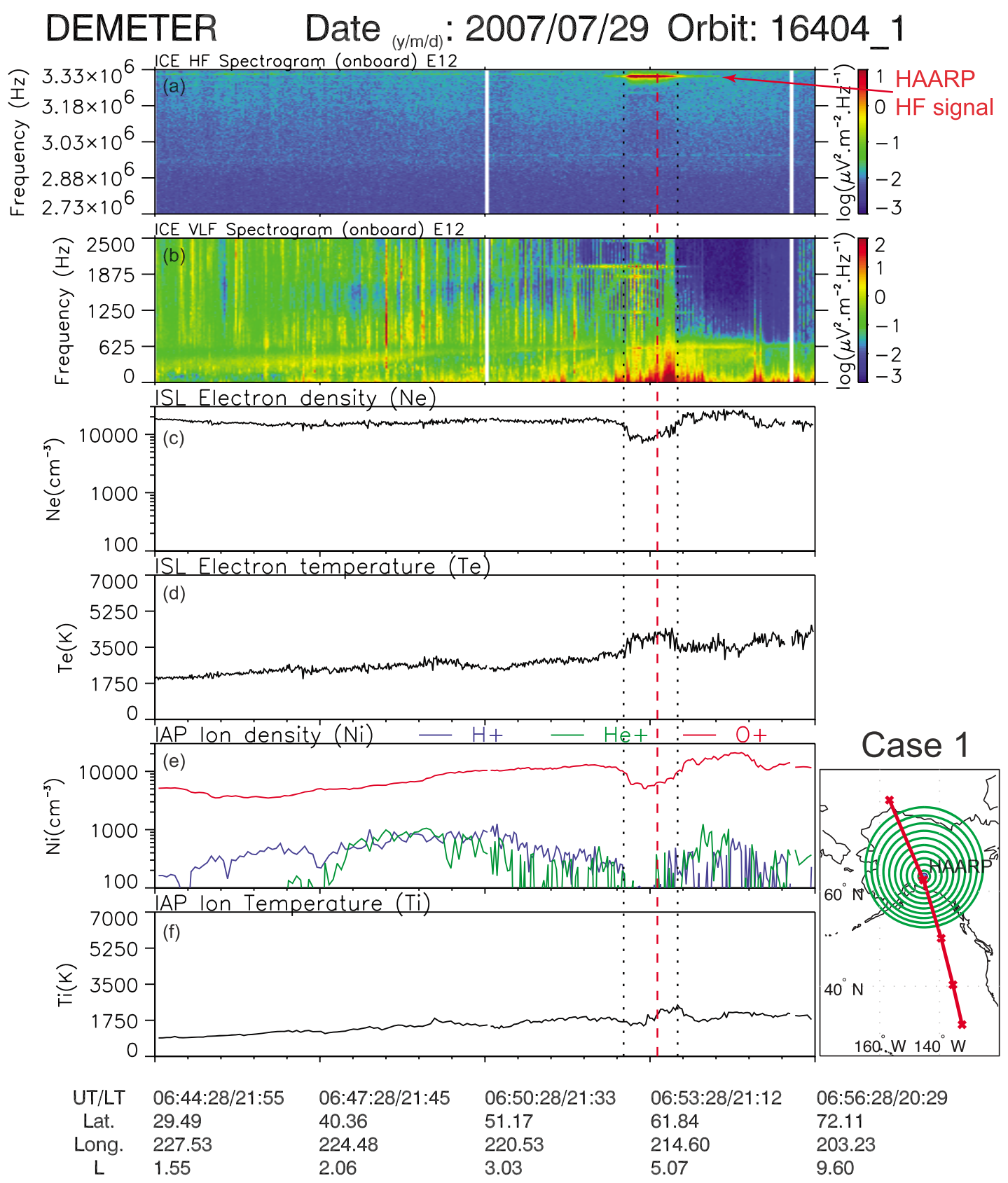

Figure 1. DEMETER observations over transmitting HAARP on 29 July 2007. (a) HF spectrogram of $E$ field showing the HAARP signal around 3.3 MHz. (b) VLF spectrogram of $E$ field showing HAARP signal, natural emissions, and ELF electrostatic turbulence. (c) Electron density, (d) electron temperature, (e) ion density, and (f) ion temperature showing the main trough over HAARP. A red dashed vertical line marks the closest approach of DEMETER to HAARP, and vertical black dotted lines mark the approximate boundaries of the main trough. The map shows the satellite projection on the ground and its relation to HAARP position. Concentric circles around HAARP are $100 \mathrm{~km}$ apart. Crosses on the satellite path correspond to time and position labels below panels. This case presents an example when the main trough is located exactly above HAARP.

ground object we refer to the distance $d$ between the subsatellite point and the object, unless specified otherwise.

\section{Observations}

\subsection{HAARP Transmitting}

[13] One of the first observed cases (we will call it Case 1), which motivated the current investigation, occurred around
06:53 UT on 29 July 2007 (Figure 1). The local time is 21:12. This DEMETER pass is relatively close to HAARP within $d=100 \mathrm{~km}$. HAARP is transmitting vertically upward a signal designed to study ELF waves on DEMETER. The format of the signal represents AM modulation of the HF carrier of $3.3 \mathrm{MHz}$ with a repeated sequence of tones of $613 \mathrm{~Hz}$ (1 sec long) and $2011 \mathrm{~Hz}(1 \mathrm{sec})$, and a ramp from 0 to $2 \mathrm{kHz}(2 \mathrm{sec})$. X mode polarization is used. Table 1 summarizes 
Table 1. Parameters of HAARP Transmissions

\begin{tabular}{ccccccc}
\hline Case & Date and Time $^{\mathrm{a}}$ UT & HF Power $(\mathrm{kW})$ & HF Frequency $(\mathrm{MHz})$ & Polarization & Modulation & $d(\mathrm{~km})$ \\
\hline 1 & 29 July 2007 06:53 & 3560 & 3.30 & X & AM & 60 \\
2 & 26 February 2007 07:10 & 3540 & 3.25 & X & AM & 210 \\
3 & 19 March 2008 07:03 & 3600 & 2.75 & X & AM & 230 \\
4 & 30 April 2007 06:40 & 0 & - & - & - & 150 \\
5 & 21 September 2007 06:40 & 0 & - & - & - & 110 \\
6 & 21 April 2007 06:58 & 0 & - & - & - & 100 \\
7 & 1 December 2007 06:58 & 0 & - & O & AM & 310 \\
8 & 28 April 2007 07:16 & 3560 & 3.20 & & - & - \\
\hline
\end{tabular}

${ }^{\mathrm{a}}$ The time represents the closest approach of DEMETER. The actual HAARP operation lasted for 20 min at least.

the parameters of this and the rest of cases presented below. The detailed discussion of the ELF waves generation by HAARP is beyond the scope of this work. The ELF format modulation is given for this case only for reference.

[14] From the top spectrogram (Figure 1a), it can be clearly seen that HAARP HF waves penetrate up to the altitude of DEMETER and are observed for about $100 \mathrm{~s}$ which is equivalent to a satellite path length of $\sim 760 \mathrm{~km}$. The maxi- mum intensity is observed for $60 \mathrm{~s}$, or $450 \mathrm{~km}$. Most likely this corresponds to the main beam of the transmitter which has spread after propagation through the ionospheric plasma. For comparison, if the HF signal were propagating in free space, the width of the main lobe at DEMETER altitude at the half power level would be $200 \mathrm{~km}$, and at the level of the first zero in the radiation pattern it would be $450 \mathrm{~km}$. The maximum level of the signal was estimated to be $1 \mathrm{mV} / \mathrm{m}$.

\section{DEMETER Date $(y / \mathrm{m} / \mathrm{d}): 2007 / 07 / 29$ Orbit: $16404 \_1$}

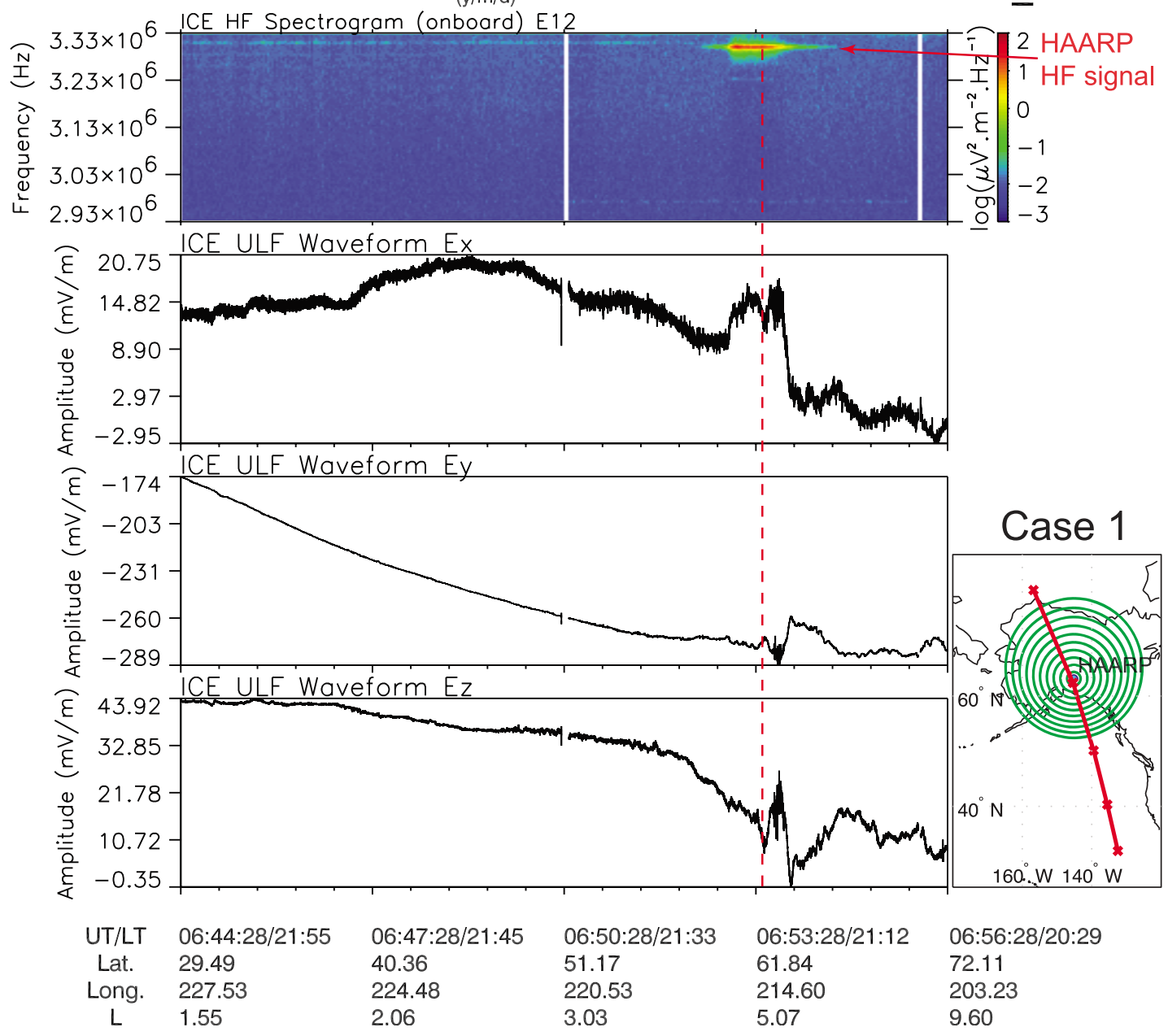

Figure 2. Additional data for Case 1 together with repeated HF spectrogram. ULF recordings (second, third, and fourth panels) in the region above HAARP show the broad scale of variations inside the main trough, from tenths to hundreds of kilometers. 


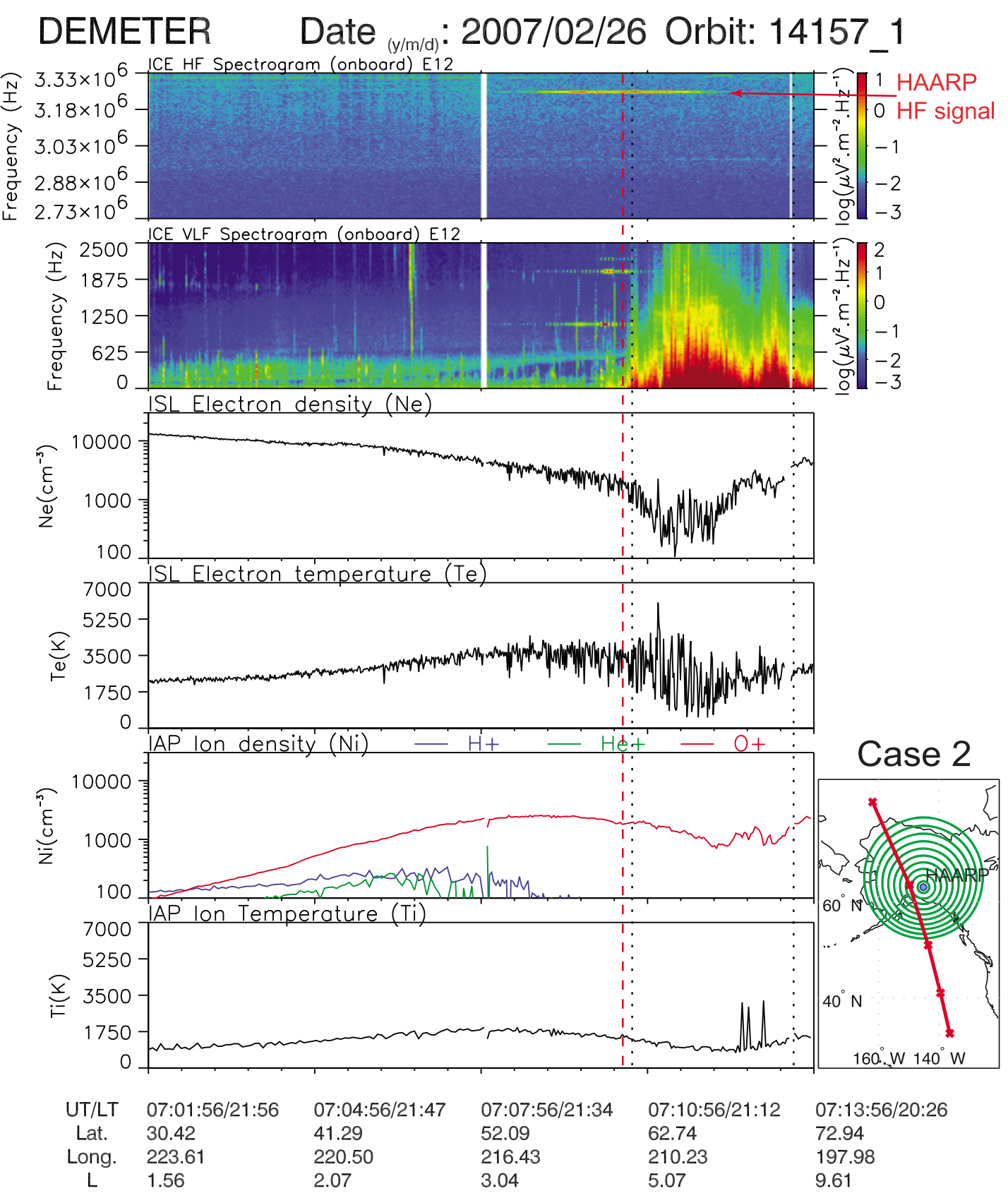

Figure 3. Images are similar to those in Figure 1. This is Case 2 on 26 February 2007 which demonstrates that perturbations (second, third, fourth, and fifth panels) can be displaced from the HAARP HF radiation (first panel) when HAARP is ON.

[15] In Figure $1 \mathrm{~b}$ natural and HAARP-generated ELF emissions in the range $0-2500 \mathrm{~Hz}$ are shown. The maxima of ELF and HF waves are separated by $\sim 100 \mathrm{~km}$ possibly because ELF radiation in the whistler mode propagates predominately along Earth's magnetic field lines [Piddyachiy et al., 2008], while HF waves propagate mostly vertically upward in this case.

[16] Figures 1c and 1d show that the electron density and temperature exhibit relatively small (less than $10 \%$ ) variations below $60^{\circ}$ latitude. From $60^{\circ}$ to $65^{\circ}$, a large-scale decrease in the electron density is observed, followed by an increase from $65^{\circ}$ to $70^{\circ}$. The electron temperature exhibits only a large-scale increase from $60^{\circ}$ to $65^{\circ}$. Also starting at $60^{\circ}$, an increase of small-scale variations in these two parameters is present. It is clear that the dominant ion density and temperature in Figures $1 \mathrm{e}$ and $1 \mathrm{f}$ show similar large-scale variations.

[17] It is interesting that in this case a region of density decrease and temperature increase corresponds exactly to the region of high HF field (Figure 1a). Also low-frequency broadband noise up to $\sim 600 \mathrm{~Hz}$ in the ELF electric field (Figure 1b) can be recognized. The magnetic component of 


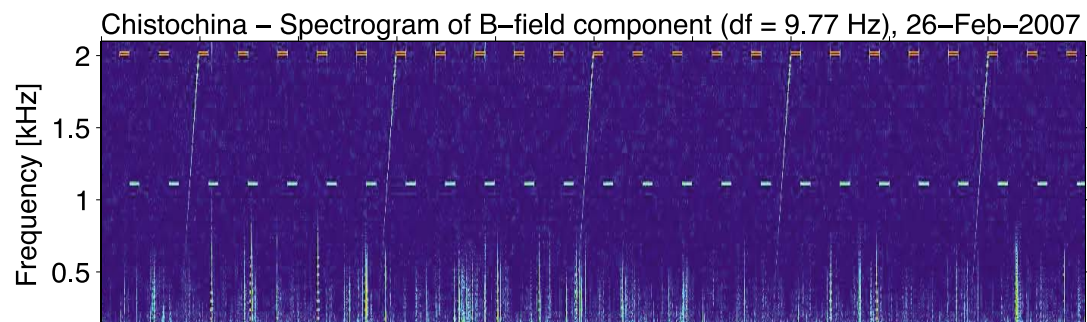

DEMETER - Spectrogram of E-field component $(\mathrm{df}=9.77 \mathrm{~Hz}$ ), 26-Feb-2007

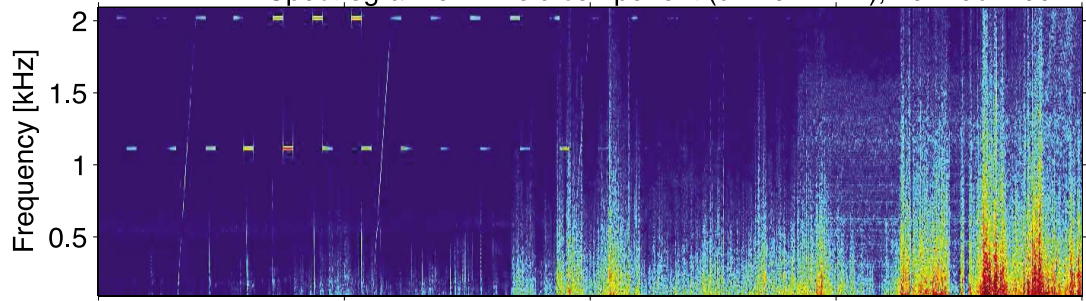

DEMETER - Spectrogram of B-field component $(\mathrm{df}=9.77 \mathrm{~Hz}), 26-\mathrm{Feb}-2007$

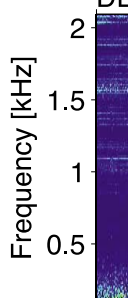

2
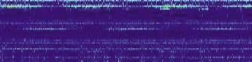

.
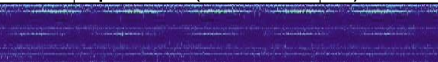

07:09:50

4.1

60.2

213.9
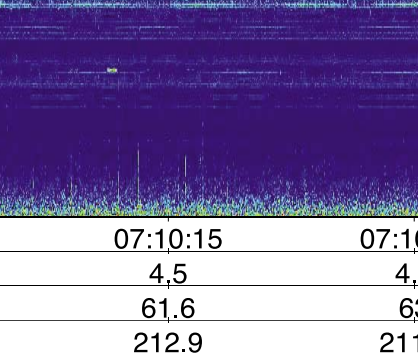

211.9

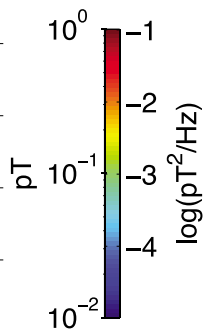

$10^{-2}$

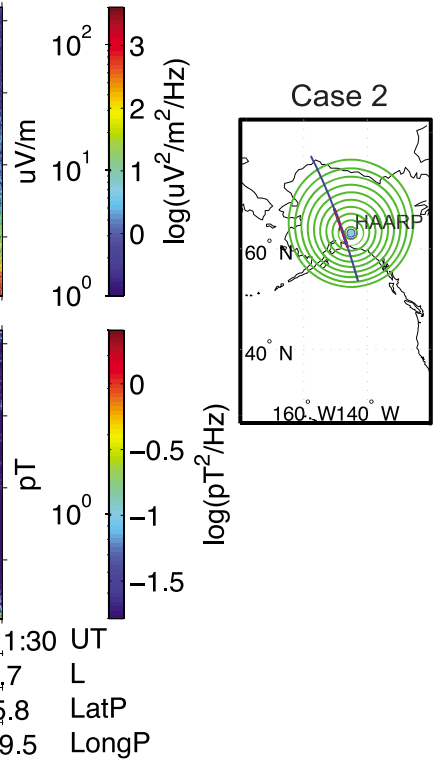

Figure 4. Additional data for Case 2. (top) Spectrogram from a ground receiver in Chistochina near HAARP. (middle and bottom) The typical high-resolution spectrograms of $E$ and $B$ fields on DEMETER in ELF range over a part of the main trough. This clearly shows that ELF electrostatic turbulence is a phenomenon that occurs only in $E$ field observations in space and not on the ground.

the ELF field (not shown here) exhibits no similar increase in noise. This broadband noise is purely electrostatic and most likely it is ELF electrostatic turbulence.

[18] Figure 2 shows the waveforms of the ULF detector for the same case. It is seen that the scale of perturbations inside the main trough is broad, i.e., from the size of the whole region of the trough (several hundreds of kilometers) to much smaller sizes of variations within the trough, and down to a minimum detectable level of tens of kilometers. Here we suppose that ULF variations are the continuation of ELF variations down to DC frequencies and that they stem from the spatial variations inside the trough. However, temporal variations may also be present, and on the moving platform they cannot be easily distinguished from spatial variations.

[19] The critical frequency of the $F$ layer measured during the pass by the HAARP digisonde is $2.225 \mathrm{MHz}$. It is definitely lower than the HAARP transmission frequency, and that is why HF easily penetrates up to DEMETER altitudes. This is a typical case for our nighttime experiments.

[20] Another HAARP/DEMETER experiment at a similar local time is presented in Figure 3 (Case 2). The HAARP HF signal in this case is seen over a much larger region (for $250 \mathrm{~s}$ or about $2000 \mathrm{~km}$ ). This is a more typical situation than in the Case 1. In such situations we most probably also see the first side lobes of the transmitter signal which are typically $15 \mathrm{~dB}$ less than the main lobe. The maximum of the ELF signal is also shifted in space with respect to the HF, but that fact is not as clear here because the HF region is more spread.

[21] The important observation in this case is that the region illuminated by the HAARP HF transmitter and the region of density irregularities generally do not coincide. Irregularities in electron density and temperature together with ELF electrostatic turbulence start at higher latitudes.

[22] Figure 4 shows a typical spectrogram of the $B$ field from a ground-based receiver in Chistochina $(30 \mathrm{~km}$ from HAARP) and typical higher-resolution ELF spectrograms of both $E$ and $B$ fields on DEMETER. It is clear that the search coil magnetometer on the satellite shows no response in the region with irregularities where ELF electrostatic turbulence is seen. The ground receiver also does not record any signals similar to electrostatic turbulence; only sferics and HAARPgenerated pulses are seen. On the ground free space EM waves are observed, and therefore the $E$ field can easily be deduced from the $B$ field measurements. This means that perturbations in the $E$ field are not present either, and there are no propagating waves associated with the ELF electrostatic turbulence that reach the ground.

[23] One more case with HAARP transmission on 19 March 2008 is shown in Figures 5 and 6 (Case 3). The behavior of HF 


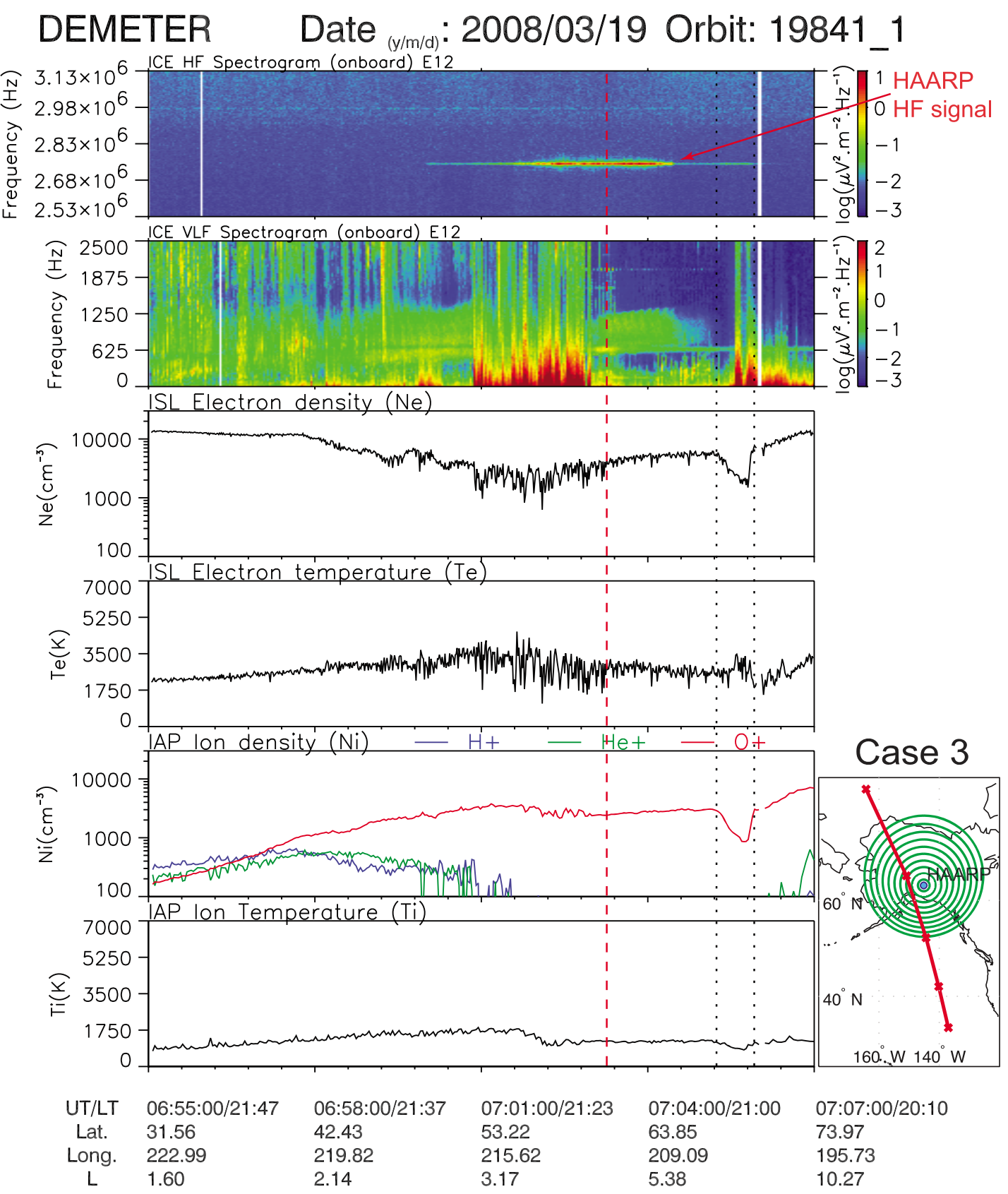

Figure 5. Images are similar to those in Figure 1. This is Case 3 on 19 March 2008. It is another example where density perturbations do not coincide with HAARP HF transmission. Here two types of density perturbations are observed as explained in the text.

and VLF HAARP-generated radiation is similar to Case 2. Here it also does not coincide with the perturbations in ion and electron densities and temperatures. In this case two types of perturbations occur. One is a confined trough in electron and ion densities around $70^{\circ}$ with corresponding ELF electrostatic turbulence. Another occurs at lower latitude and consists of electron density irregularities that are spread over a much bigger region. The second perturbation also coincides well with ELF electrostatic turbulence. Figure 6 shows that ELF electrostatic turbulence goes down to ULF frequencies which is a typical characteristic of its observation on DEMETER.

\subsection{HAARP Not Transmitting}

[24] In order to check the connection between HAARP radiation and the occurrence of density perturbations and ELF electrostatic turbulence, it is also important to look at observations of DEMETER over HAARP when the transmitter is not operating. In the case on 30 April 2007 (Figure 7, Case 4), the HAARP HF transmitter has been off for $6 \mathrm{~h}$ before, as well as during the DEMETER satellite pass. Around $55^{\circ}$ in latitude a large-scale decrease in plasma densities and increase in temperatures can be seen. After the large-scale decrease you can also see a relatively weak large-scale increase in plasma density 


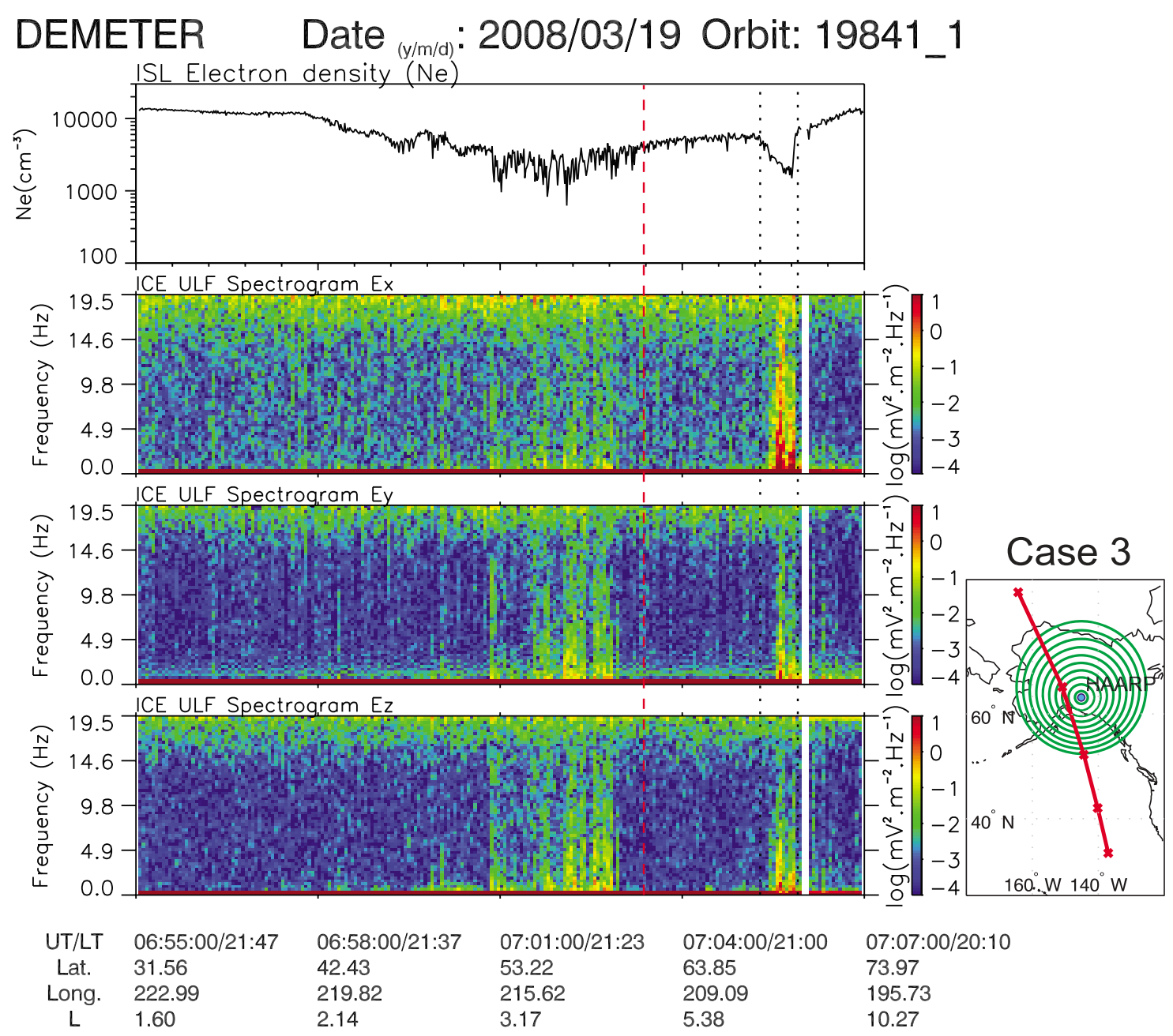

Figure 6. Additional data for Case 3 with ULF variations (second, third, and fourth panels) shown in spectrogram form. This demonstrates that ELF electrostatic turbulence is observed on DEMETER down to the DC $E$ field.

similar to the Case 1. In addition, there are smaller-scale perturbations within large-scale changes. ELF electrostatic turbulence is also clearly seen in the same region.

[25] Generally, the form of the density variations observed above and around the HAARP region is substantially variable. However, the main feature of these variations, the density decrease of about an order of magnitude that lies within $50^{\circ}-$ $70^{\circ}$ and extends for $5^{\circ}-10^{\circ}$, is the most commonly observed large-scale variation. Two additional examples shown in Figures 8 and 9 (Cases 5 and 6) can shed more light on the different forms of troughs observed. HAARP was not transmitting for these cases so that we see purely natural variations. In Case 5 as in Case 3 we see at first small-scale perturbations and then a pronounced trough in densities with small-scale variations inside. In Case 6 , the density trough is confined to a specific region that is similar to case 1. It is interesting that in this example ELF electrostatic turbulence is not seen continuously within the trough. This probably is the result of the mostly smooth density within the trough. This supports previous observations that ELF electrostatic turbulence is first of all associated not with the trough itself but with commonly observed density variations within it [Kelley, 1972]. Similar situations were observed in several other cases.

[26] Since the main emphasis of the current work is devoted to the HAARP region, we limited our discussion to data from this region. However, the main ionospheric trough on DEMETER is observed in other high- and middle-latitude regions of the ionosphere. In general, the structure of the trough and the ELF electrostatic turbulence is similar to the cases presented above for the region over HAARP.

\subsection{Statistics}

[27] In total, 100 cases over the HAARP region have been analyzed. The summary of this analysis is presented in Table 2 . The cases included into statistics are those when the satellite is within a distance $d<350 \mathrm{~km}$ from HAARP. The cases are sorted by the conditions when they occur. The number of cases for each condition is shown in square brackets. The daytime passes of DEMETER always happen from around 11:30 to 12:30 LT (20:30-21:30 UT), while nighttime passes occur from around 21:30 to 22:30 LT (06:30-07:30 UT). If the transmitter was operating during 


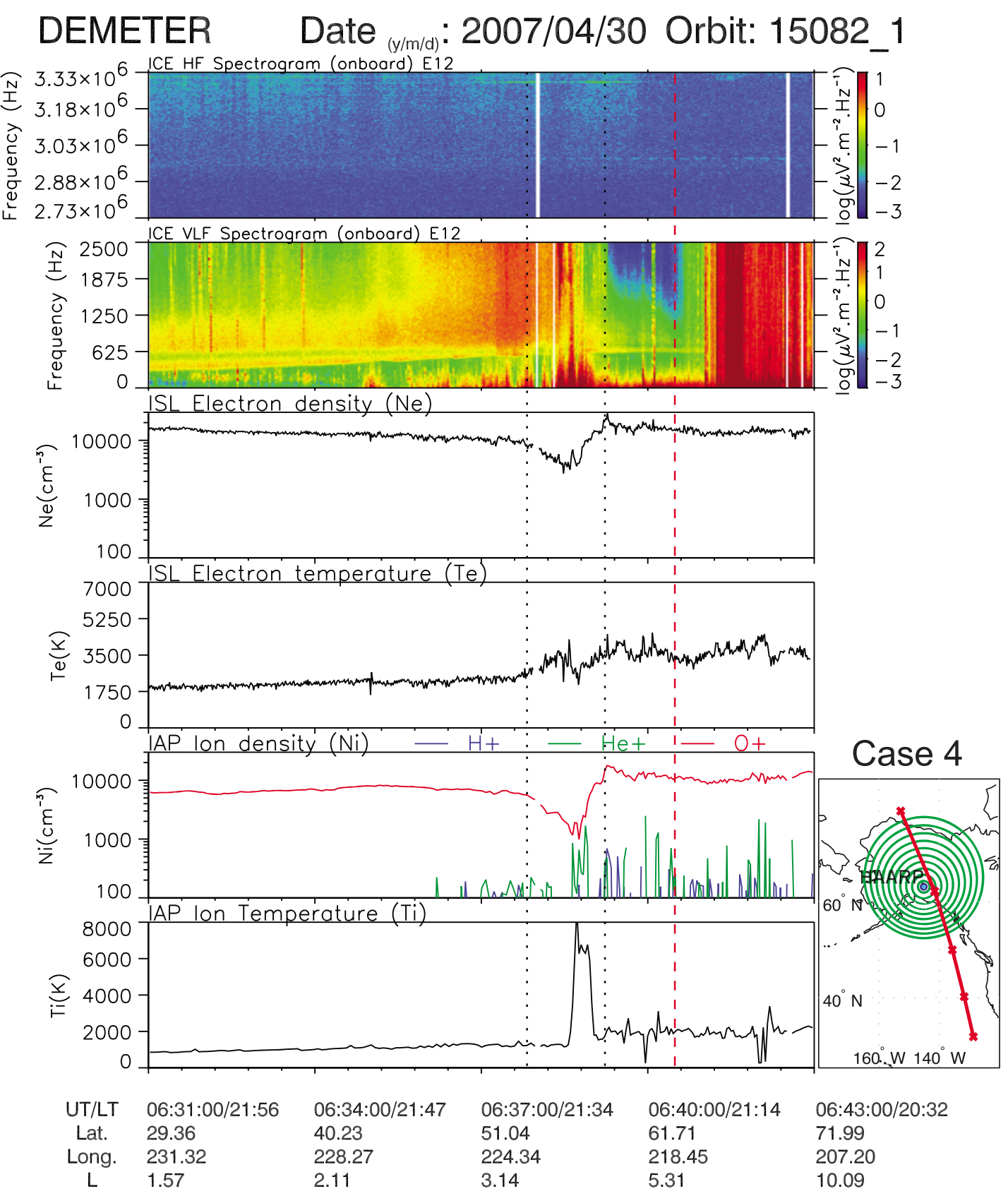

Figure 7. Images are similar to those in Figure 1. This is Case 4 on 30 April 2007. HAARP was turned off for $6 \mathrm{~h}$ before the satellite pass. Perturbations associated with the main trough are clearly visible around latitude of $55^{\circ}$ and are displaced from the HAARP location.

the pass and at least several minutes before, then such condition is specified as HAARP ON. For condition to be called HAARP OFF the transmitter should be off during the pass and at least for 30 minutes before the pass.

[28] The results of visual analysis of every case were classified into three categories depending on electron density behavior. "No trough or variations" is assigned to the case when variations over HAARP are less than $30 \%$ or variations are smooth; that is, the change occurs over the distance of more than $200 \mathrm{~km}$. Such density behavior can be seen in Cases 1, 2, 4 and 6 below $50^{\circ}$ latitude. For example, the small variation around 06:48:30 UT on 29 July 2007 (Case 1) or smooth variation from 06:52 to 06:58 UT on 21 April 2007 (Case 6) would be classified as "no variation". Cases fall into categories with "trough/variations" only when more than $30 \%$ change in electron density is observed over the distance less than $200 \mathrm{~km}$ as in the cases presented above. Sometimes the variations occur in a relatively confined region like in the regions marked with dotted lines in Case 1, Case 3, and Case 6. Sometimes the region is not well defined from the electron density as in Case 2 . Then the location of the main trough is determined from the position 


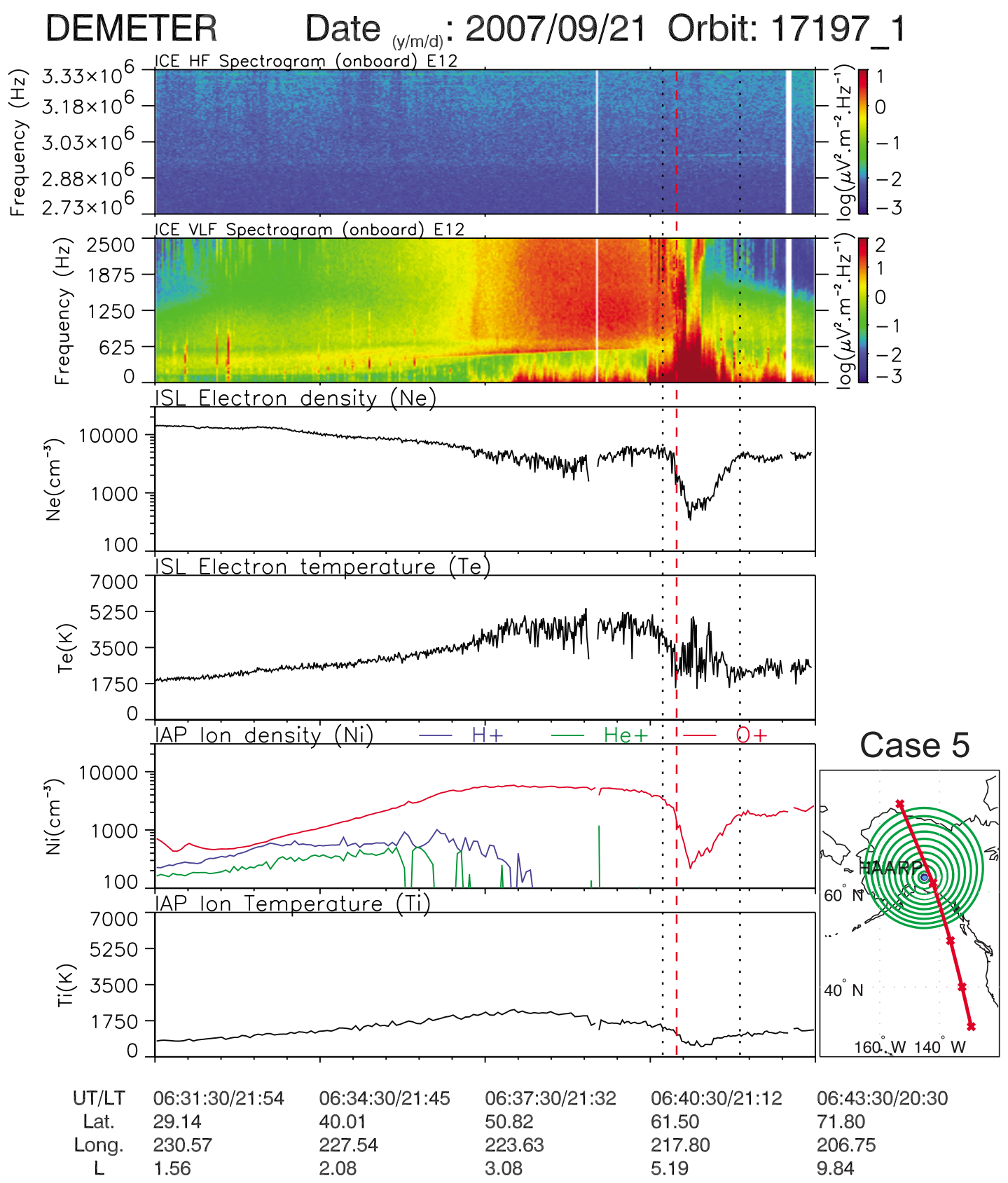

Figure 8. Images are similar to those in Figure 1. This is Case 5 on 21 September 2007. HAARP was turned off for $7 \mathrm{~h}$ before the satellite pass. The HAARP is located within the perturbations associated with the main trough.

of the corresponding ELF electrostatic turbulence. The perturbation is considered to be ELF electrostatic turbulence if it extends up to at least $300 \mathrm{~Hz}$ and the power spectral density exceeds $\sim 10 \mu V^{2} / \mathrm{m}^{2} / \mathrm{Hz}$. The cases when neither of these approaches work were not included in the analysis. Both of the types of variations are categorized as "trough/ variations". If the closest approach to HAARP occurs within a variation region then the case is put in the category "over HAARP". There are cases when due to variations inside the trough, ISL data processing does not work properly and produces no acceptable results (Figure 10). In this case an interpolation of only a few reasonable data points is made, and as a result the electron density is usually recorded as a constant equal to $1000 \mathrm{~cm}^{-3}$. Those cases were also classified as ones with variations.

[29] The most important conclusion which follows from Table 2 is that HAARP operation does not correlate with large-scale density or temperature variations over HAARP. For daytime, such variations have not been observed at all, whether HAARP was ON or OFF. This is the reason why the statistics were limited to only 20 cases in the daytime. For nighttime, large-scale variations appear in 32 cases out 
DEMETER Date (y/m/d) $_{2}: 2007 / 04 / 21$ Orbit: $14950 \_1$

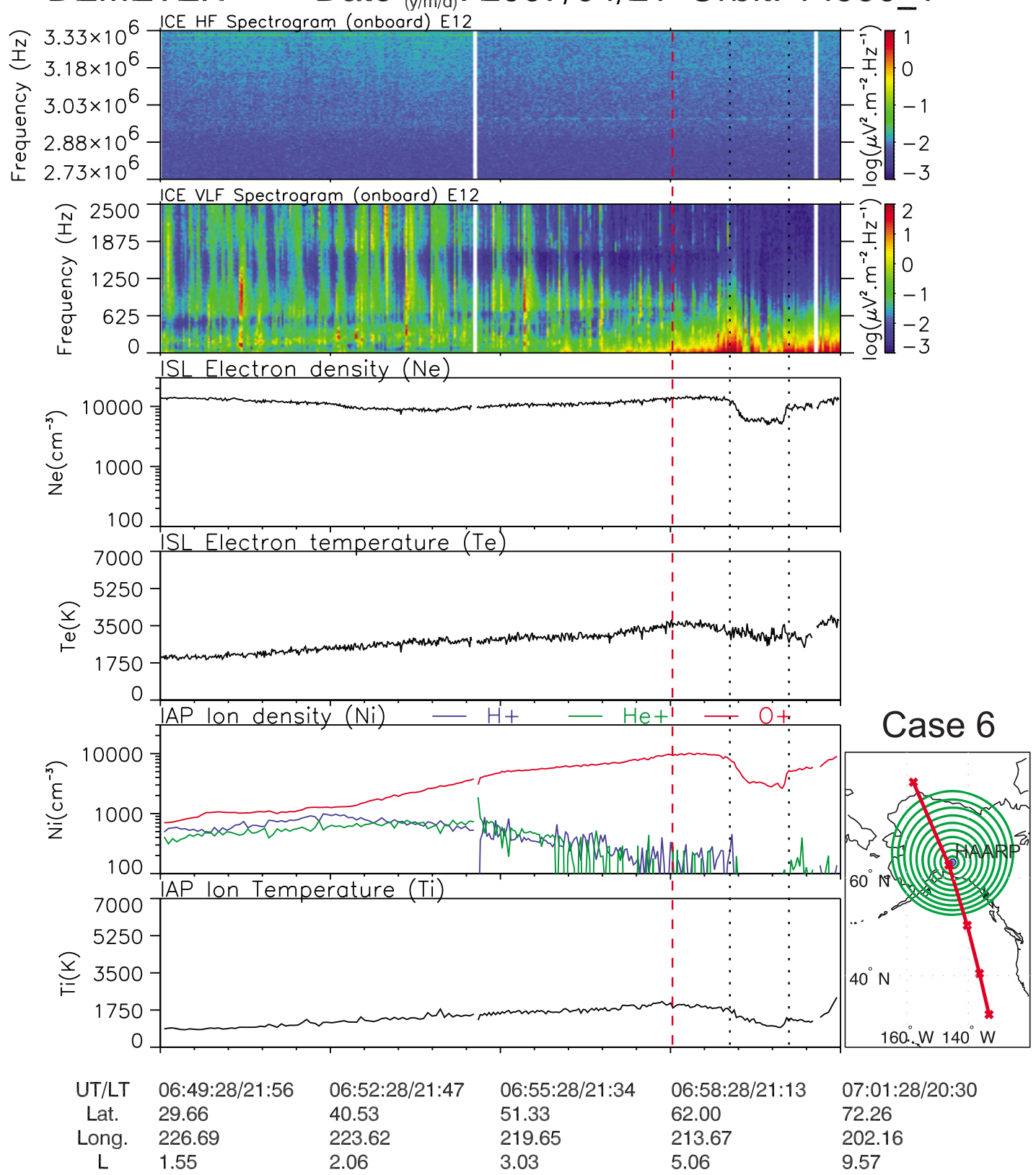

Figure 9. Images are similar to those in Figure 1. This is Case 6 on 21 April 2007. HAARP was turned off for $2 \mathrm{~h}$ before the satellite pass. Perturbations associated with the main trough are displaced from the HAARP location.

Table 2. Summary of Observations ${ }^{\mathrm{a}}$

\begin{tabular}{lcccc}
\hline & & \multicolumn{2}{c}{ Results } \\
\cline { 3 - 5 } & Conditions & $\begin{array}{c}\text { No Trough or } \\
\text { No Variations }\end{array}$ & $\begin{array}{c}\text { Trough/Variations Displaced } \\
\text { From HAARP }\end{array}$ & $\begin{array}{c}\text { Trough/Variations } \\
\text { Over HAARP }\end{array}$ \\
\hline \multirow{2}{*}{ Daytime[20] } & HAARP ON[12] & 12 & 0 & 0 \\
\multirow{2}{*}{ Nighttime[80] } & HAARP OFF[8] & 8 & 0 & 0 \\
& HAARP ON[40] & 8 & 11 (Cases 2 and 3) & 21 (Case 1) \\
& HAARP OFF[40] & 8 & 7 (Cases 4 and 6) & 25 (Cases 5, 7, and 8) \\
\hline
\end{tabular}

${ }^{\mathrm{a}}$ Total number of cases and specific cases discussed in the text. 


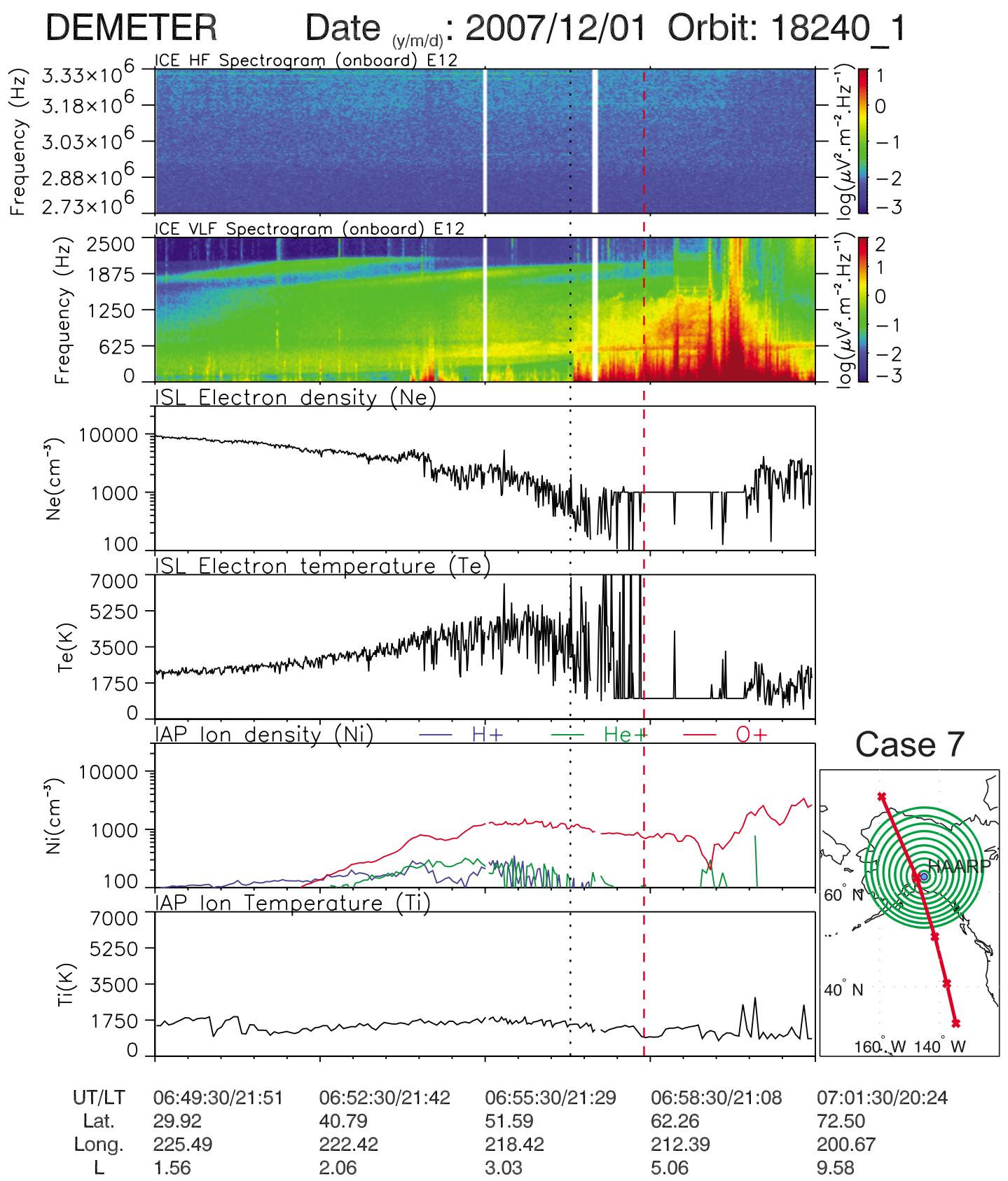

Figure 10. Images are similar to those in Figure 1. This is Case 7 on 1 December 2007. HAARP was turned off for many days before the satellite pass. The flat response in electron density is produced because of the ISL instrument limitations and not due to HF heating.

of 40 when HAARP is ON and in 32 out of 40 when HAARP is OFF. Moreover, there are 21 cases with variations over HAARP when HAARP is ON versus 25 cases with variations over HAARP when HAARP is OFF. This suggests that the variations are not caused by HAARP.

[30] We can also see that the region above HAARP is disturbed in more than half of the number of cases at nighttime. However, in many such cases the large-scale variations occupy the whole region of high latitudes, and the region above HAARP is just a part of it. That is why there are not many cases in the "Trough/variations displaced from
HAARP" category since in such cases variations should be localized and not over HAARP.

\section{Discussion and Comparison With Other Recent Experiments}

[31] In the work of Milikh et al. [2008, Figures 3 and 4] two cases were presented in an attempt to show DEMETER observations of ionospheric ducts. It is clear that in both cases the main ionospheric trough is present during the observations. We can see sharp minima from 06:54:30 to 


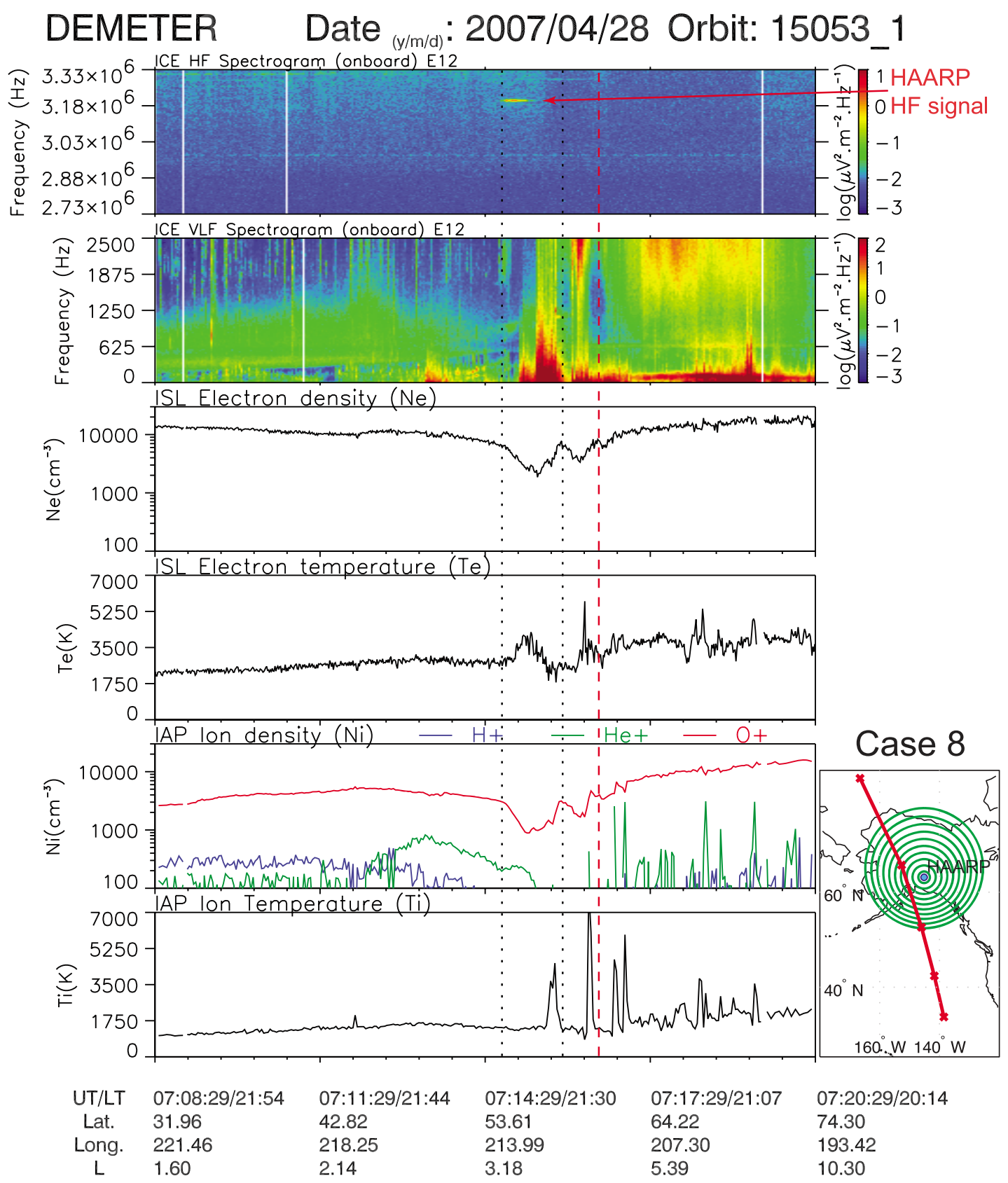

Figure 11. Images are similar to those in Figure 1. Here the observation of the HF signal from HAARP coincide with the location of the main trough and not with the location of HAARP which is about $5^{\circ}$ higher than that. This suggests guiding of HF waves by the trough.

06:55:00 UT on 24 April 2007 and from 06:45:30 to 06:47:10 UT on 1 August 2007. The authors claim that "both the ion temperature and $\mathrm{O}^{+}$density rise due to the $\mathrm{HF}$ heating by about $60 \%-70 \%$ " and that there is "a duct associated with the density gradient between 06:51:00 and 06:51:30" on 24 April 2007. Also they refer to "a series of few percent short length ducts between 06:52:00 and 06:53:30". Our observations demonstrate that similar gradients and short length ducts can be observed by DEMETER when HAARP is OFF like in Cases 6 and 7 of the current work. It is typical to see irregularities of various scales around the trough, and in such situations HAARP might have affected plasma density but it is hard to prove it with only satellite observations because of the possible presence of the ionospheric trough.

[32] In the work given by Wong et al. [2009, Figures 1 and 2] it was claimed that an electron hole was created by high-power auroral simulations in the cases presented. However, it appears that in those cases we see only an instrumental effect in the region of large density variations which is typical of high latitudes. The same instrumental effect of constant density at the $1000 \mathrm{~cm}^{-3}$ level is presented in Figure 10. It was observed in several cases when HF transmitters were OFF. 
[33] From the observations presented here, it is seen that at high latitudes, large-scale irregularities are very common at nighttime. Sometimes they occur together with a clear trough in plasma density, but this is not the case all the time. The most important implication for HF heater related research is that such natural irregularities would often prevent the detection of effects like ducts or holes created by a heater. However, it does not mean that such effects cannot exist and cannot be detected. This rather means that natural effects should be taken into account in experimental techniques. For instance, one can try to select times of observations when the ionospheric density is relatively undisturbed. Unfortunately, daytime is not the best choice because HF waves will not usually penetrate through the higher density ionosphere during the day. However, as seen from statistics there exist days without irregularities over HAARP during nighttime.

[34] Plasma convection at high latitudes should also be taken into account during experimental observations of density variations. It is well known that at high latitudes the typical speed of plasma flow in the $F$ layer is several hundred $\mathrm{m} / \mathrm{s}$ in the horizontal direction [Hunsucker and Hargreaves, 2003]. Thus if some density variations in the $F$ layer are created by an HF heater in a region with a horizontal extent of $100-200 \mathrm{~km}$, then in about 10 minutes the plasma with density variations will move away from this region if the heater is turned OFF. (That is why for statistics with turned OFF HF heater we included only cases for which the HF transmitter is OFF for at least 30 minutes before the satellite pass.) This implies that for an effect to be observed on a satellite in the $F$ layer it should have a timescale of development of no more than 10 minutes, and averaging over longer timescales would also not be beneficial.

[35] Finally, it is supposed that in cases similar to Case 1 when the trough location coincides closely with the location of the HF maximum on a satellite, the HF may in fact have been guided by a natural density duct to the satellite. For instance, for Case 1 the region of HF detection on the satellite is unusually confined. Most often the region of HF detection spreads over longer distances, as seen from other cases. However, such confinement of HF to the trough region does not always happen. Another strong case that supports the theory of HF guidance by a natural density duct is presented in Figure 11. In this case HF waves were also detected in a confined region inside the trough, and the trough was not directly over HAARP but about $5^{\circ}$ lower in latitude. The HF beam was actually directed along magnetic field line which crosses DEMETER altitude at $61^{\circ}$. However, the HF signal is seen at latitudes from $55^{\circ}$ to $57^{\circ}$ where the trough is located at the time of observation.

\section{Summary}

[36] In this work we analyzed electron and ion density variations together with HF recordings aboard the DEMETER satellite mainly in relation with HAARP HF transmitter operations. First, we conducted case studies and established that the primary cause of the large-scale irregularities in the highlatitude ionospheric $F$ layer is the main ionospheric trough. We showed that large-scale variations associated with the trough can reach an order of magnitude and extend over a large region from about $50^{\circ}$ to $70^{\circ}$ in latitude. Such variations definitely complicate the observations of possible density variation effects caused by HAARP and should be taken into account in any relevant experiment. Then, we carried out the statistical analysis of 100 cases with different conditions that is summarized in Table 2. No correlation between density variations and HAARP HF transmitter operation was found.

[37] Another preliminary conclusion was made about HF waves interacting with natural density variations. Several cases presented in the work suggest that HF waves can be guided by natural density ducts within the region of the main ionospheric trough. However, many cases were also seen when such guiding is not observed.

[38] Acknowledgments. The Stanford portion of this work was supported by the Defense Advanced Research Projects Agency (DARPA) and the High Frequency Active Auroral Research Program (HAARP) under ONR grants N00014-05-1-0854 to Stanford University. We thank all HAARP facility staff for conducting many days and long-duration experiments including those during late at night. This work could not have been done without the experience of HAARP operators Michael McCarrick, David Seafolk-Kopp, and Helio Zwi. We thank Paul Kossey and Edward Kennedy for help with organization of campaigns. We also thank all personnel of DEMETER satellite mission and especially Jean-Yves Brochot and Stephanie Berthelin.

[39] Robert Lysak thanks the reviewers for their assistance in evaluating this paper.

\section{References}

Berthelier, J. J., et al. (2006), ICE, the electric field experiment on DEMETER, Planet. Space Sci., 54(5), 456-471, doi:10.1016/j.pss.2005.10.016.

Berthelier, J.-J., M. Malingre, R. Pfaff, E. Seran, R. Pottelette, J. Jasperse, J.-P. Lebreton, and M. Parrot (2008), Lightning-induced plasma turbulence and ion heating in equatorial ionospheric depletions, Nat. Geosci., 1, 101-105, doi:10.1038/ngeo109.

Hunsucker, R. D., and J. K. Hargreaves (2003), The High-Latitude Ionosphere and its Effects on Radio Propagation, Cambridge Univ. Press, Cambridge, U. K.

James, H. G., R. L. Dowden, M. T. Rietveld, P. Stubbe, and H. Kopka (1984), Simultaneous observations of ELF waves from an artificially modulated auroral electrojet in space and on the ground, J. Geophys. Res., 89, 1655-1666.

Kelley, M. C. (1972), Relationship between electrostatic turbulence and spread F, J. Geophys. Res., 77, 1327-1329, doi:10.1029/JA077i007p01327.

Kelley, M. C. (2009), The Earth's Ionosphere: Plasma Physics and Electrodynamics, Int. Geophys. Ser., Elsevier, Amsterdam.

Kennedy, E. J., and P. Kossey (2002), Description of the HAARP Gakona facility with some results from recent research, paper presented at XXVIIth General Assembly of International Union of Radio Science, Maastricht, Neth., 17-24 Aug.

Lebreton, J.-P., et al. (2006), The ISL Langmuir probe experiment processing onboard DEMETER: Scientific objectives, description and first results, Planet. Space Sci., 54(5), 472-486, doi:10.1016/j.pss.2005.10.017.

Milikh, G. M., K. Papadopoulos, H. Shroff, C. L. Chang, T. Wallace, E. V. Mishin, M. Parrot, and J. J. Berthelier (2008), Formation of artificial ionospheric ducts, Geophys. Res. Lett., 35, L17104, doi:10.1029/2008GL034630.

Moore, R. C., U. S. Inan, T. F. Bell, and E. J. Kennedy (2007), ELF waves generated by modulated HF heating of the auroral electrojet and observed at a ground distance of $4400 \mathrm{~km}, J$. Geophys. Res., 112, A05309, doi:10.1029/ 2006JA012063.

Parrot, M. (Ed.) (2006), Special issue: First results of the DEMETER micro-satellite, Planet. Space Sci., 54(5), 411-558.

Piddyachiy, D., U. S. Inan, T. F. Bell, N. G. Lehtinen, and M. Parrot (2008), DEMETER observations of an intense upgoing column of ELF/VLF radiation excited by the HAARP HF heater, J. Geophys. Res., 113, A10308, doi:10.1029/2008JA013208.

Rodger, A. S., R. J. Moffett, and S. Quegan (1992), The role of ion drift in the formation of ionization troughs in the mid- and high-latitude ionosphere: A review, J. Atmos. Terr. Phys., 54, 1-30, doi:10.1016/0021-9169(92) 90082-V.

Temerin, M. (1978), The polarization, frequency, and wavelengths of highlatitude turbulence, J. Geophys. Res., 83, 2609-2616, doi:10.1029/ JA083iA06p02609.

Wong, A. Y., J. Chen, L. C. Lee, and L. Y. Liu (2009), Observation of largescale density cavities and parametric-decay instabilities in the high-altitude 
discrete auroral ionosphere under pulsed electromagnetic radiation, Phys. Rev. Lett., 102, 105002, doi:10.1103/PhysRevLett.102.105002.

T. F. Bell, U. S. Inan, and D. Piddyachiy, Department of Electrical Engineering, Stanford University, 350 Serra Mall, Packard Bldg., Room 308, Stanford, CA 94305, USA. (depi@stanford.edu)
J.-J. Berthelier, Centre d'Etudes des Environnements Terrestre et Planétaires, IPSL, CETP 4, av. de Neptune, Saint-Maur-des-Fossés F-94100, France.

M. Parrot, Laboratoire de Physique et Chimie de l'Environnement, CNRS, $3 \mathrm{~A}$ av. de la Recherche Scientifique, Orléans F-45071 CEDEX 2, France. 